\title{
Intonation of parentheses in spontaneous French sentences
}

Philippe Martin

EA333 ARP, UFRL, Université Paris Diderot, France

https://doi.org/10.36505/ExLing-2008/02/0040/000099

\begin{abstract}
Traditionally, parentheses have been described by phoneticians as speech segments with lower intensity, restrained pitch variation and speech rate faster than the rest of the sentence. This iconic coding may be found in some examples of read (prepared) speech, but spontaneous speech data tend to show that specific prosodic mechanisms do exist to either 1) integrate the syntactic parenthesis into the overall prosodic structure of the sentence or 2) isolate it with an independent prosodic structure. The realizations chosen by speakers appear to be dictated by the interaction of semantic, syntactic and prosodic markers to ensure the parentheses will be identified as such by listeners.
\end{abstract}

Key words: intonation, parenthesis, prosodic structure, macrosyntax

\section{Theoretical background}

In the theoretical background developed by GARS in Aix-en-Provence, a sentence, in spontaneous speech, can be analyzed in 5 distinct macrosyntactic types: 1) the Kernel (Noyau), which can form a syntactically and prosodically well formed autonomous speech unit, and optionally 2) one or more Prefixes, preceding the Kernel; 3) one or more Parentheses, imbedded in a Prefix or in the Kernel; 4) one or more Postfixes and 5) one or more Suffixes. Postfixes and Suffixes are both placed after the Kernel, and differ by the nature of the dependency relation which links them to the Kernel: Postfixes use a prosodic dependency relation manifested by specific contours on their final stressed syllables (flat contours in the declarative case), whereas Suffixes are linked to the Kernel with a syntactic, or possibly semantic, relation. In this arrangement, a canonical parenthesis is a verbal construction which interrupts the progression of another verbal construction or a sequence of verbal constructions (Blanche-Benveniste, 1997).

Various types of syntactic parentheses can be considered:

a) Inside a macrosegment stress group: in the sequence est-ce que nous sommes je lance le débat du même coup hein est-ce que nous sommes euh prêts? [Retraites] the parenthesis je lance le débat du même coup hein is inserted in the stress group nous sommes prêts between the auxiliary sommes and the adjective prêts and is followed by a copy of the segment interrupted est-ce que nous sommes;

ExLing 2008: Proceedings of 2nd Tutorial and Research Workshop on Experimental Linguistics, 25-27 August 2008, Athens, Greece 
b) Between stress groups of a macrosegment (Kernel, Prefix, Postfix or Suffix), as in the example la fonction publique [...] c'est pas du tout l'emploi à vie la mobilité professionnelle est très forte dans la fonction publique mais c'est le salaire à vie [retraites], where the Parenthesis is located inside the Kernel c'est pas du tout l'emploi à vie mais c'est le salaire à vie, but not inside a Kernel stress group;

c) Between two macrosegments. In the latter configuration it is often difficult to differentiate the parenthesis from a Prefix if it appears before the Kernel and from a Suffix when it occurs after the Kernel. In the example, without intonation, the parenthesis can also be considered as a Prefix: après tu ouvres les feuillets comme un livre et avec la lumière du soleil il faut absolument qu'il y ait le soleil + il y a une ombre portée de la colonne vertébrale qui te dit que là il y a un poisson ou autre chose [fossiles].

Macrosegments are syntactically "floating" in the sentence, i.e. no syntactic dependency relation organizes their possible hierarchy, which is defined by intonation, i.e. by the prosodic structure. Furthermore, the Kernel is always associated to a well formed prosodic structure. This is due to the nature of prosodic dependency relations in French where prosodic markers signal a dependency to the right. Therefore the Kernel constitutes a well formed sequence both syntactically and prosodically. This can be tested experimentally by isolating a Kernel macrosegment with a sound editor, as the resulting sequence should be perceived by itself as complete and well formed independently.

As seen above, Parentheses are macrosegments inserted somewhere either inside a stress group, between stress groups in a macrosegment, or between macrosegments. Aligned with text parentheses, prosodic segments exist either independent or integrated in the overall prosodic structure of the sentence. In the last case, these segments end with a rising continuation contour, whereas independent segments end with a falling terminal contour.

\section{Prosodic parentheses}

Debaisieux and Martin (2007) conducted an experimental analysis based on the macrosyntactic approach described above, hunting for totally well formed and complete prosodic structures which could be inserted inside the Kernel. Despite the relatively large number of experimental data analyzing the final prosodic movement in some 200 spontaneous speech examples, only 22 examples showed a final falling melodic contour, the majority of the other sentences exhibiting a rising contour. No clear correlation could be found between rising or falling contours ending the parentheses and the nature of the conjunction that introduces them (si, parce que, comme, 
puisque, enfin), or the lack of such introductory unit. No correlation was found either with the position of the parenthesis inside the sentence (inside stress groups, between stress groups, between macrosegments).

\section{Combinatorial analysis}

If we consider the sentence organized into two syntactic and prosodic lines, some syntactic, semantic or prosodic markers must operate at both ends of the parenthetical macrosegments to indicate its nature to the listeners. These markers could appear either on the preceding macrosegment or at the beginning of the parenthesis to indicate the left boundary, and at the end of the parenthesis or at the beginning of the following macrosegment to mark its right boundary (Fig. 1).

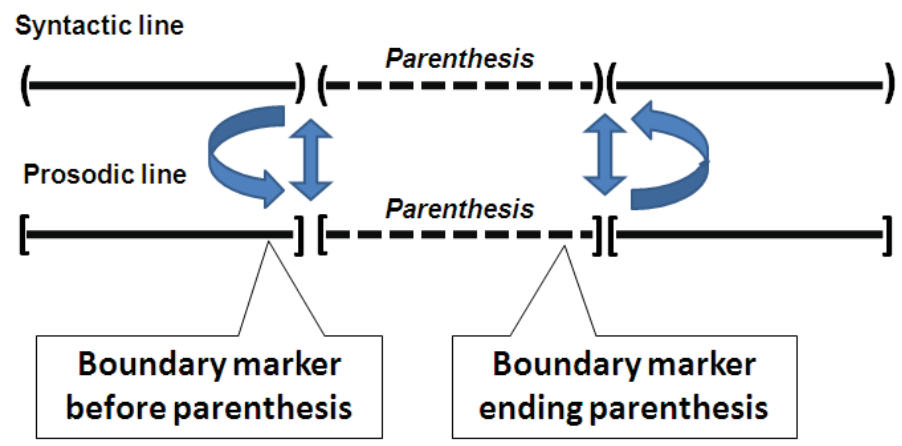

Figure 1. Syntactic and prosodic markers of parenthetical macrosegments.

Representing by A, B and C the text line units (unit B being the parenthesis), and $\mathrm{a}, \mathrm{b}$ and $\mathrm{c}$ the prosodic units (unit $\mathrm{b}$ being the prosodic unit align with the text parenthesis), and denoting by $\mathrm{X}$ and $\mathrm{x}$ the presence of a marker located at the end of each text or prosodic unit, 8 cases are possible:

No prosodic marker:

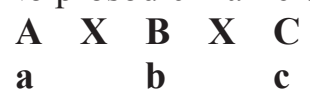

Complete or partial prosodic redundancy:
$\begin{array}{llllll}A & \mathbf{X} & \mathbf{B} & \mathbf{X} & \mathbf{C}\end{array}$
$\begin{array}{lllllllllll}A & \mathbf{X} & \mathbf{B} & \mathbf{X} & \mathbf{C}\end{array}$
$\begin{array}{lllll}\mathbf{A} & \mathbf{X} & \mathbf{B} & \mathbf{X} & \mathbf{C}\end{array}$
$\begin{array}{llllll}\mathbf{a} & \mathbf{x} & \mathbf{b} & \mathbf{x} & \mathbf{c}\end{array}$
$\begin{array}{lllll}\mathbf{a} & \mathbf{x} & \mathbf{b} & \mathbf{c}\end{array}$
$\begin{array}{lllll}\mathbf{a} & \mathbf{b} & \mathbf{x} & \mathbf{c}\end{array}$

Syntactic marker starting unit $\mathbf{C}$ (reprise):
A
B $\quad \mathbf{X} \quad \mathbf{C}$
A
B $\quad \mathbf{X} \quad \mathbf{C}$
A $\quad$ B $\quad \mathbf{X} \quad \mathbf{C}$
$\begin{array}{lllll}\mathbf{a} & \mathbf{x} & \mathbf{b} & \mathbf{x} & \mathbf{c}\end{array}$
a $\mathbf{x} \quad \mathbf{b}$
c
a $\quad \mathbf{b} \quad \mathbf{x} \quad \mathbf{c}$

No syntactic marker (parenthesis non introduced by a conjunction:
A $\quad$ B $\quad$ C

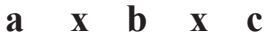


Considering these combinatorial possibilities, it becomes clear that we cannot expect all syntactic and prosodic markers to be effectively present in a given realization. In particular, prosodic markers, mostly through the presence of a rising or falling melodic contour located on the last stressed syllable of the parenthetical macrosegment, simply reveal the integration of the parenthesis into the overall prosodic structure of the sentence, or on the contrary by a falling contour the presence of an independent prosodic structure imbedded in the overall prosodic structure of the sentence. If this approach is correct, prosodic markers will be always present if no other semantic or syntactic marker is present. Indeed data showed that 18 cases out of 22 parentheses ending with a falling contour are correlated with non introduced parentheses with no text reprisal after their end.

\section{Conclusion}

Since no clear correlation has been found between the characteristics of parenthesis and their syntactic properties, in particular between their position in the macrosyntactic structure (inside the Kernel, between Prefixes, etc.) and the particular conjunction (or their absence) that introduced them, another view must be considered. As prosodic parentheses can function independently from the syntactic parentheses, our data suggest that the congruence between the prosodic and syntactic parentheses is only obligatory when no other markers, syntactic or semantic, are used by the speaker.

\section{References}

Blanche-Benveniste, C. 1997. Approches de la langue parlée en français. Paris : Ophrys.

Debaisieux, J-M. et Deulofeu, H-J. 2006. Cohérence et syntaxe : le rôle des connecteurs. in Frédéric Calas, (éd) Cohérence et discours. PUPS. Paris, 197-207.

Debaisieux, J-M. et Martin, Ph. 2008. Les parenthèses : étude macrosyntaxique et prosodique sur corpus. M. J. Beguelin and M. Avanzi (ed.) Actes du $\mathrm{I}^{\circ}$ Colloque international de macro-syntaxe "La parataxe" (Neuchâtel 12-15 février 2007), Tubinger: Niemeyer.

Gachet, F. et Avanzi, M. 2008. Les parenthèses en français parlé : étude prosodique. Communication aux Journées Conscila, «Les parenthèses en français », 14 mars 2008, Paris, ENS Ulm.

Martin, Ph. 2006. Intonation du français: parole spontanée et parole lue, Estudios de Fonética Experimental, Vol XV, 2006, Barcelona, 133-162. 